Nota

\title{
REGENERAÇÃo IN VITRO DE Passiflora suberosa A PARTIR DE DISCOS FOLIARES
}

\author{
Alessandra Cristina Boffino de Almeida Monteiro ${ }^{1,4}$; Gerson Tokio Nakazawa ${ }^{2}$; Beatriz Madalena \\ Januzzi Mendes ${ }^{3}$; Adriana Pinheiro Martinelli Rodriguez ${ }^{3 *}$ \\ ${ }^{1}$ Pós-Graduanda do Depto. de Ciências Biológicas - USP/ESALQ, C.P. 9 - CEP: 13418-900 - Piracicaba, SP. \\ ${ }_{3}^{2}$ Graduando em Engenharia Agronômica - USP/ESALQ. \\ ${ }^{3}$ Lab.de Biotecnologia Vegetal - USP/CENA, C.P. 96 - CEP: 13400-970 - Piracicaba, SP. \\ ${ }^{4}$ Bolsista FAPESP. \\ *Autor correspondente <adriana@cena.usp.br>
}

RESUMO: A regeneração in vitro de plantas de Passiflora suberosa foi obtida a partir de discos foliares. Folhas foram retiradas de plantas germinadas em casa de vegetação, imersas em solução comercial de hipoclorito de sódio (3:1), durante 20 minutos. Discos foliares de $0,5 \mathrm{~cm}$ de diâmetro, com a face adaxial em contato com o meio de cultura, foram introduzidos em placa de petri. Organogênese foi obtida utilizando-se meio MS acrescido de 0,5 ou 1,0 $\mathrm{mg} \mathrm{L}^{-1}$ de BAP (6-benzilaminopurina). Após 4 a 8 semanas, observou-se formação de calos nas bordas dos discos foliares. Os calos formados foram transferidos para meio MSM, acrescido de 1,0 $\mathrm{mg} \mathrm{L}^{-1}$ de $\mathrm{GA}_{3}$ (ácido giberélico), sob fotoperíodo de 16 horas. Desenvolvimento de gemas adventícias foi obtido a partir dos calos, sendo estas alongadas e enraizadas no mesmo meio de cultura, após periódicas repicagens, e aclimatadas em casa de vegetação.

Palavras-chave: BAP (6-benzilaminopurina), cultura de tecido, organogênese

\section{IN VITRO REGENERATION OF Passiflora suberosa FROM LEAF DISCS}

\begin{abstract}
In vitro regeneration of plantlets was obtained from Passiflora suberosa leaf discs. Leaves from plants germinated in the greenhouse were collected and immersed in commercial sodium hypochlorite solution (3:1), during 20 minutes. Leaf discs $(0.5 \mathrm{~cm}$ in diameter) were obtained and placed with the adaxial side in contact with the culture medium in petri dishes. Organogenesis was obtained when MS medium was supplemented with 0.5 or $1.0 \mathrm{mg} \mathrm{L}^{-1}$ BAP (6-benzylaminopurine), after four to eight weeks, callus proliferated from the edge of the discs. After induction, calli were transferred to modified MS media supplemented with1.0 $\mathrm{mg} \mathrm{L}^{-1} \mathrm{GA}_{3}$, under 16-hour photoperiod. Development of adventitious shoots was obtained from the callus tissues and the shoots were elongated and rooted in the same culture medium and acclimatized in the greenhouse.

Key words: BAP (6-benzilaminopurina), tissue culture, organogenesis
\end{abstract}

\section{INTRODUÇÃO}

Passiflora suberosa é uma das espécies de maior variabilidade no gênero, apresentando variação intra-específica no conjunto cromossômico diplóide, a saber, $2 n=12$, 24 e 36 cromossomos (Otoni et al., 1996). Interesse por esta espécie tem sido demonstrado por estudos realizados nas áreas de medicina farmacêutica, fitopatologia e cultura de tecidos. P. suberosa foi apontada como fonte de resistência ao vírus do endurecimento dos frutos do maracujazeiro (Otoni et al., 1996), além de apresentar resistência ao fungo Fusarium oxysporum f. sp. passiflorae, causador da seca vascular (Gardner, 1989). Um glicosídeo cianogênico ciclopentenóide, denominado de passisuberosina, foi isolado de P. suberosa, (Spencer \& Segler, 1987), segundo Conn (1981) este composto é um precursor do ácido cianídrico. Cromatografia e espectrometria de extratos de frutos de $P$. suberosa mostraram que estes são ricos em antocianinas, apresentando oito diferentes tipos (Kidoy et al., 1997). Pruthi et al. (1961) sugeriram que as antocianinas, obtidas da casca dos frutos do maracujá roxo (Passiflora edulis), podem ser utilizadas como corante natural.

Alguns autores relatam o cultivo in vitro de $P$. suberosa, utilizando explantes como folhas, segmentos nodais e internodais e gemas apicais (Drew, 1991; Scorza \& Janick, 1980). Drew (1991), trabalhando com $P$. suberosa, obteve plantas utilizando como explante gemas e segmentos nodais, cultivados em meio contendo $150 \mu \mathrm{M}$ de $2 \mathrm{iP}$ (isopenteniladenina) e 17,1 $\mu \mathrm{M}$ de IAA (ácido indolacético). Florescimento in vitro foi obtido por Scorza \& Janick (1980), utilizando internó de P. suberosa cultivados em $0,1 \mathrm{mg} \mathrm{L}^{-1}$ de BAP, sob condições de fotoperíodo. Isolamento de protoplastos a partir de mesófilo de P. suberosa foi obtido por Otoni et al. (1996). A influência da idade das plantas fornecedoras de explantes no isolamento dos protoplastos foi avaliada.

O estabelecimento de um sistema de regeneração in vitro de plantas de $P$. suberosa pode ser importante para aplicação em programas de melhoramento genético do gênero Passiflora, ou para propagação do 
maracujazeiro. Através do florescimento e frutificação in vitro, pode-se isolar dos frutos, corantes, como as antocianinas. Técnicas de hibridação somática podem ser utilizadas para obtenção de plantas resistentes a doenças com potencialidade para utilização como porta-enxerto. Este trabalho teve como objetivo a indução de gemas adventícias e posterior regeneração de plantas, a partir de discos de folha de $P$. suberosa.

\section{MATERIAL E MÉTODOS}

Folhas jovens de plantas de Passiflora suberosa germinadas e cultivadas em vasos, em casa de vegetação, foram coletadas para obtenção de explantes. A assepsia foi feita com solução comercial de hipoclorito de sódio, na proporção de $3: 1$, durante 20 minutos, seguida de três lavagens, com água esterilizada, em câmara asséptica.

Para indução de organogênese utilizou-se o meio MS (Murashige \& Skoog, 1962), acrescido de $30 \mathrm{~g} \mathrm{~L}^{-1}$ de sacarose, $8 \mathrm{~g} \mathrm{~L}^{-1}$ de ágar e concentrações de BAP (6benzilaminopurina), 0,$0 ; 0,5$; ou $1,0 \mathrm{mg} \mathrm{L}^{-1}$. O pH foi ajustado a 5,8, o meio autoclavado e vertido em placas de petri (100 $\times 15 \mathrm{~mm})$.

Discos foliares de $5 \mathrm{~mm}$ de diâmetro foram colocados com a face adaxial em contato com o meio de cultura. Cada tratamento constou de doze repetições, cada uma sendo constituída de uma placa de petri contendo dez explantes. O experimento foi instalado seguindo-se o delineamento experimental inteiramente ao acaso. As culturas foram mantidas no escuro a $26 \pm 2 \mathrm{C}$, durante quatro semanas. Após esse período, com o auxílio de microscópio estereoscópico, os explantes foram avaliados quanto à formação de calo ou gemas adventícias.

Os calos e as bordas dos explantes foram transferidos para meio MSM (Monteiro et al., 1999b) acrescido de $1,0 \mathrm{mg} \mathrm{L}^{-1}$ de $\mathrm{GA}_{3}$, mantidos sob fotoperíodo de 16 horas, a $27 \pm 1 \mathrm{C}$, sendo subcultivados a cada quatro semanas.

As plântulas obtidas e enraizadas in vitro foram transferidas para copos descartáveis de $500 \mathrm{~mL}$, contendo substrato irrigado (Plantmax) com solução nutritiva, cobertos com sacos plásticos transparentes, os quais foram abertos gradativamente.

\section{RESULTADOS E DISCUSSÃO}

Avaliação dos explantes após quatro semanas em meio de indução, no escuro, mostrou que no tratamento testemunha não se observou formação de calo em nenhum dos discos (Figura 1a), observando-se apenas leve oxidação nas bordas dos explantes. Nos tratamentos contendo BAP, observou-se formação de calo em 100\% dos explantes. Esta formação ocorreu nas bordas dos discos de folha cultivados em meio contendo 0,5 ou $1,0 \mathrm{mg} \mathrm{L}^{-1}$ de BAP (Figura 1b-c). Os calos apresentavam
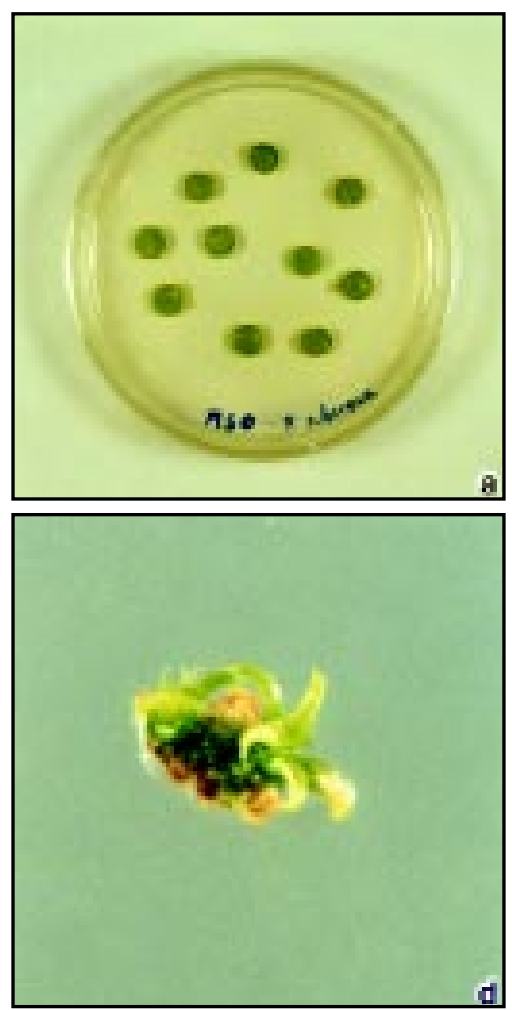
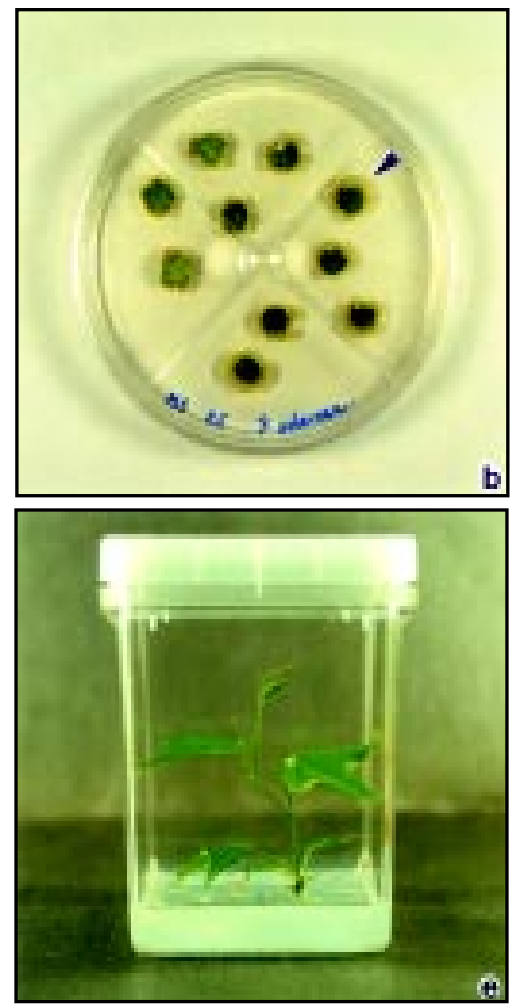
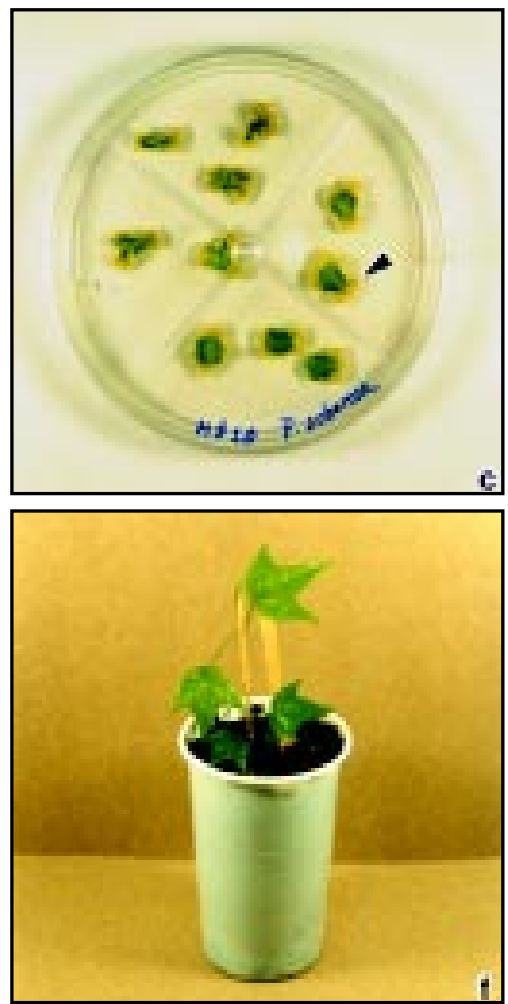

Figura 1 - Organogênese a partir de discos foliares de $P$. suberosa. a) discos cultivados por quatro semanas em meio MS sem regulador vegetal, sem formação de calo; b-c) discos cultivados em meio contendo $0,5 \mathrm{~m} \mathrm{~L}^{-1}$ (b) ou 1,0 mg L-1 (c) de BAP, apresentando proliferação de calos nas bordas (setas), após quatro semanas; d) gema em fase inicial de desenvolvimento formada em meio de cultura contendo BAP, cultivada em meio $\mathrm{MSM}+1,0 \mathrm{mg} \mathrm{L}^{-1}$ de $\mathrm{GA}_{3}$, sob fotoperíodo; e) plântula enraizada in vitro, mostrando bom desenvolvimento de parte aérea e raízes; f) planta aclimatada, após retirada do saco plástico, em casa de vegetação. 
aspecto organogênico, com coloração amarelo-esverdeada e textura friável, sendo semelhante em coloração, textura e quantidade em ambos os tratamentos com BAP.

A formação de gemas foi observada a partir dos calos, após o cultivo em meio MSM $+1,0 \mathrm{mg} \mathrm{L}^{-1}$ de $\mathrm{GA}_{3}$, sob condições de 16 horas de fotoperíodo. Inicialmente, observou-se a presença de pontos esverdeados nos calos, seguido do desenvolvimento de gemas, em ambos os tratamentos contendo BAP. As gemas regeneradas (Figura 1d) foram isoladas dos calos, transferidas para meio fresco (MSM + 1,0 mg L-1 $\mathrm{GA}_{3}$ ), sendo subcultivadas a cada 28 dias. Apesar da formação de calo ter ocorrido em $100 \%$ dos explantes, a formação de gemas foi considerada baixa, com obtenção de apenas quatro plântulas, que foram posteriormente aclimatadas.

A resposta observada nos discos de folha de $P$. suberosa difere da organogênese observada em $P$. edulis f. flavicarpa a partir do mesmo explante e regulador vegetal. Nesta espécie, a formação das gemas ocorre direta ou indiretamente, sendo os calos de coloração esbranquiçada, de textura compacta (Monteiro et al., 1999a). As gemas são formadas durante as primeiras semanas, ainda em meio contendo BAP, no escuro. Em $P$. suberosa, as gemas não são observadas no meio de indução, sendo formadas posteriormente, em meio MSM contendo $\mathrm{GA}_{3}$, sob condições de luz. Enraizamento foi observado após individualização e crescimento das gemas em meio de alongamento, não havendo necessidade do cultivo das plântulas em meio contendo auxinas, comumente utilizado para enraizamento in vitro. A formação de raízes em $P$. edulis f. flavicarpa também ocorre em meio MSM acrescido de $1,0 \mathrm{mg} \mathrm{L}^{-1}$ de $\mathrm{GA}_{3}$ (Monteiro et al., 1999b). Drew (1991), trabalhando com diferentes espécies de Passiflora, inclusive $P$. suberosa, observou a formação de gemas adventícias e calos a partir de segmentos nodais. O enraizamento das plântulas ocorreu em meio MS contendo $5 \mu \mathrm{M}$ de IAA $\left(0,87 \mathrm{mg} \mathrm{L}^{-1}\right)$.

As plântulas obtidas, cerca de quatro meses após a indução (Figura 1e), foram aclimatadas em casa de vegetação (Figura 1f), sendo periodicamente irrigadas com solução nutritiva.

\section{CONCLUSÕES}

O método utilizado para regeneração de plantas de Passiflora suberosa a partir de discos de folha mostrase eficiente. Os explantes respondem aos tratamentos contendo $\operatorname{BAP}\left(0,5\right.$ ou $\left.1,0 \mathrm{mg} \mathrm{L}^{-1}\right)$, formando inicialmente calo e posteriormente gemas, desenvolvendo-se e enraizando em meio de cultura contendo $1,0 \mathrm{mg} \mathrm{L}^{-1}$ de $\mathrm{GA}_{3}$.

\section{AGRADECIMENTO}

À FAPESP pela concessão de bolsa de mestrado.

\section{REFERÊNCIAS BIBLIOGRÁFICAS}

CONN, E.E. Cyanogenic glycosides. The Biochemistry of Plants, v.7, p.479-500, 1981.

DREW, R.A. In vitro culture of adult and juvenile bud explants of Passiflora species. Plant Cell, Tissue and Organ Culture, v.26, p.23-27, 1991.

GARDNER, D.E. Pathogenecity of Fusarium oxyporum f. sp. passiflorae to Banana Poka and other Passiflora spp. in Hawaii. Plant Diasease, v.73, p.476-478, 1989.

KIDOY, L.; NYGARD, A.M.; ANDERSON, O.M.; PEDERSEN, A.T.; AKSNES, D.W.; KIREMIRE, B.T. Anthocyanins in fruits of Passiflora edulis and Passiflora suberosa. Journal of Food Composition and Analysis, v.10, p.49-54, 1997.

MONTEIRO, A.C.B. de A.; MENDES, B.M.J.; RODRIGUEZ, A.P.M. Effect of benzylaminopurine and thidiazuron on leaf discs of Passiflora spp cultivated in vitro. In: CONGRESS ON IN VITRO BIOLOGY, New Orlans, 1999. Addendum booklet. New Orlans: Society For In Vitro Biology, 1999a. p.13.

MONTEIRO, A.C.B. de A.; HIGASHI, E.N.; GONÇALVES, A.N.; RODRIGUEZ, A.P.M. Culture medium optimization of yellow passionfruit (Passiflora edulis f. flavicarpa). In: CONGRESS ON IN VITRO BIOLOGY, New Orlans, 1999. Addendum booklet. New Orlans: Society For In Vitro Biology, 1999b. p.12.

MURASHIGE, T.; SKOOG, F. A revised medium for rapid growth and bioassays with tobacco tissue cultures. Physiologia Plantarum, v.15, p 473-497, 1962.

OTONI, W.C.; CASALI, V.W.D.; POWER, J.B.; DAVEY, M.R. Isolamento de protoplastos de mesófilo de $P$. suberosa $L$.: influência da idade das plantas matrizes. Revista Ceres, v.43, p.157-164, 1996.

PRUTHI, J.S.; SUSHEELA, R.; LAL, G. Anthocyanin Pigment in Passion Fruit Rind. Journal of Food Science, v.26, p.385-388, 1961.

SCORZA, R.; JANICK, J. In vitro flowering of Passiflora suberosa L. Journal of the American Society for Horticultural Science, v.105, p.892-897, 1980.

SPENCER, K.C.; SEGLER, D.S. Passisuberosin and epipassisuberosin: two cyclopentenoid cyanogenic glycosides from P. suberosa. Phytochemistry, v.26, p.1665-1667, 1987.

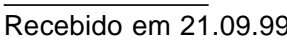

